\title{
Effect of Leucas aspera on hepatotoxicity in rats
}

Leucas aspera (LA), belonging to the family Labiatae, is commonly called as 'chota halkusa'. It grows as a weed on wastelands and roadsides all over India. The plant is used as an insecticide and indicated in traditional medicine for coughs, colds, painful swellings, and chronic skin eruptions. ${ }^{[1]}$ Compounds isolated from the plant include, long-chain aliphatic compounds, a triterpene-leucolactone, sterols- sitosterol, campesterol, stigmasterol and a novel phenolic compound. ${ }^{[2-5]}$

Although LA is an ingredient of polyherbal liver-protective Siddha formulations (Siddhar Hepato capsule- Siddhar Pharma, Chennai, India), it has never been systematically investigated for hepatoprotective activity. Hence, the present study is aimed to evaluate the protective activity of LA in carbon tetrachloride $\left(\mathrm{CCl}_{4}\right)$-induced hepatotoxicity in rats.

The herb in full bloom was collected, washed, aerial parts separated, air dried, powdered, and soaked in methanol for $72 \mathrm{~h}$. The extract was then filtered, concentrated under vacuum, and lyophilised to obtain a solid mass $(18 \% \mathrm{w} / \mathrm{w})$. Preliminary phytochemical analysis of the extract revealed the presence of flavonoids, reducing sugars, sterols, alkaloids, saponins, and volatile terpenes.

Swiss albino mice were used for toxicity study, while the hepatoprotective study was carried out in adult male Wistar rats (150-200 g). The rats were housed in clean polypropylene cages and fed with commercial rat chow and water ad libitum. Permission was obtained from the institutional animal ethics committee for the study. For acute toxicity study, four groups of two mice each were administered i.p. methanolic extract of LA at 200, 800, 1200 and $2000 \mathrm{mg} / \mathrm{kg}$ The animals were continuously observed for $1 \mathrm{~h}$, then frequently for $24 \mathrm{~h}$, and thereafter once per day for 14 days. There was no lethality in any of the groups. One-tenth of the maximum tested dose (i.e., $200 \mathrm{mg} / \mathrm{kg}$, p.o.) of the extract was selected for the evaluation of antihepatotoxic activity.

For hepatoprotective study, a total of 30 rats were divided into five groups ( $n=6$ in each group). Group I (vehicle control) and Group II (CCl -treated control) were given $5 \%$ gum acacia ( $2 \mathrm{ml} / \mathrm{kg}$, b.w.) p.o for 5 days. Groups III and IV were pretreated with methanolic extract of LA (200 and $400 \mathrm{mg} / \mathrm{kg}$, p.o.; respectively) for 5 days, while Group $\mathrm{V}$ was pretreated with silymarin (100 mg/kg, p.o.), a known hepatoprotective agent for 5 days. Liver damage was induced in all groups (except Group I) with 1:1 (v/v) mixture of $\mathrm{CCl}_{4}$ and olive oil $(1 \mathrm{ml} / \mathrm{kg}$, s.c.) injected on days 2 and 3 while olive oil ( $2 \mathrm{ml} / \mathrm{kg}$, s.c.) was injected to Group I. ${ }^{[6]}$

After $48 \mathrm{~h}$ of $\mathrm{CCl}_{4}$ treatment, that is, on the sixth day, the animals were killed under light ether anesthesia. Blood was withdrawn from the carotid artery, allowed to coagulate at $37^{\circ} \mathrm{C}$ for $30 \mathrm{~min}$, serum separated by centrifugation at 2500 rpm and analysed for serum glutamate oxaloacetate (SGOT) and serum glutamate pyruvate transaminase (SGPT). ${ }^{[7]}$ The livers of the rats were promptly excised, serially sectioned, fixed in $10 \%$ formalin and 5 micron section were stained with haematoxylin and eosin for histopathological study. The results were statistically analysed using one-way analysis of variance (ANOVA) followed by Dunnett's test for individual comparisons. $\mathrm{P}<0.01$ were considered significant.

In experimental hepatopathy, the toxin $\left(\mathrm{CCl}_{4}\right)$ is biotransformed by cytochrome $\mathrm{P} 450$ to produce the trichloromethyl free radical. This in turn elicits lipid peroxidation of membrane lipids in the presence of oxygen generated by metabolic leakage from mitochondria. All these events culminate in loss of integrity of cell membranes and damage of hepatic tissue. ${ }^{[8]}$

Assessment of liver function can be made by estimating the activities of serum GPT and GOT, which are enzymes originally present in higher concentration in cytoplasm. When there is hepatopathy, these enzymes leak into the blood stream in conformity with the extent of liver damage. The elevated levels of these marker enzymes in $\mathrm{CCl}_{4}$-treated rats in the present study corresponded to the extensive liver damage induced by the toxin. Pretreatment with the test drug LA (in both doses) as well as the standard drug silymarin significantly $(\mathrm{P}<0.01)$ reduced the elevation in liver enzymes, thereby showing that LA has hepatoprotective action (Table 1)

Comparative histopathological study of the liver from different groups of rats corroborated the hepatoprotective efficacy of LA (Figure 1). Various pathological changes like steatosis, centrilobular necrosis, and vacuolisation seen in Group II rats were prevented to a moderate extent in Groups

Table 1

Effect of Leucas aspera (LA) on serum GOT, GPT levels in $\mathrm{CCl}_{4}$ induced hepatoxicity in rats

\begin{tabular}{|c|c|c|c|}
\hline Group & Treatment & $\begin{array}{c}\text { SGOT } \\
(U / L)\end{array}$ & $\begin{array}{c}\text { SGPT } \\
(U / L)\end{array}$ \\
\hline I & Control & $47 \pm 6$ & $50 \pm 3.8$ \\
\hline II & $\mathrm{CCl}_{4}$ & $95 \pm 3.8^{*}$ & $83 \pm 6.3^{*}$ \\
\hline III & $\mathrm{LA}(200 \mathrm{mg} / \mathrm{kg})+\mathrm{CCl}_{4}$ & $70 \pm 4.9^{* *}$ & $51 \pm 5^{\star *}$ \\
\hline IV & $\mathrm{LA}(400 \mathrm{mg} / \mathrm{kg})+\mathrm{CCl}_{4}$ & $52 \pm 3.7^{* *}$ & $72 \pm 6.5^{* *}$ \\
\hline V & Silymarin $(100 \mathrm{mg} / \mathrm{kg})+\mathrm{CCl}_{4}$ & $45 \pm 5.8^{\star *}$ & $36 \pm 4.7^{* *}$ \\
\hline One-wa & ay & 13.46 & 10.03 \\
\hline ANOVA & $P$ & $<0.01$ & $<0.01$ \\
\hline
\end{tabular}

Values are mean $\pm \mathrm{SEM} ; \mathrm{n}=6$ in each group; $\mathrm{df}=3,20 ;{ }^{*} \mathrm{P}<0.01$ as compared to group I, ${ }^{* *} \mathrm{P}<0.01$ as compared to group II. $\mathrm{CCl}_{4}$ was administered s.c. and the other substances were given orally. 
Figure 1. Photo micrographs of liver sections stained with haematoxylin and eosin $\left(\mathrm{X}_{100}\right)$

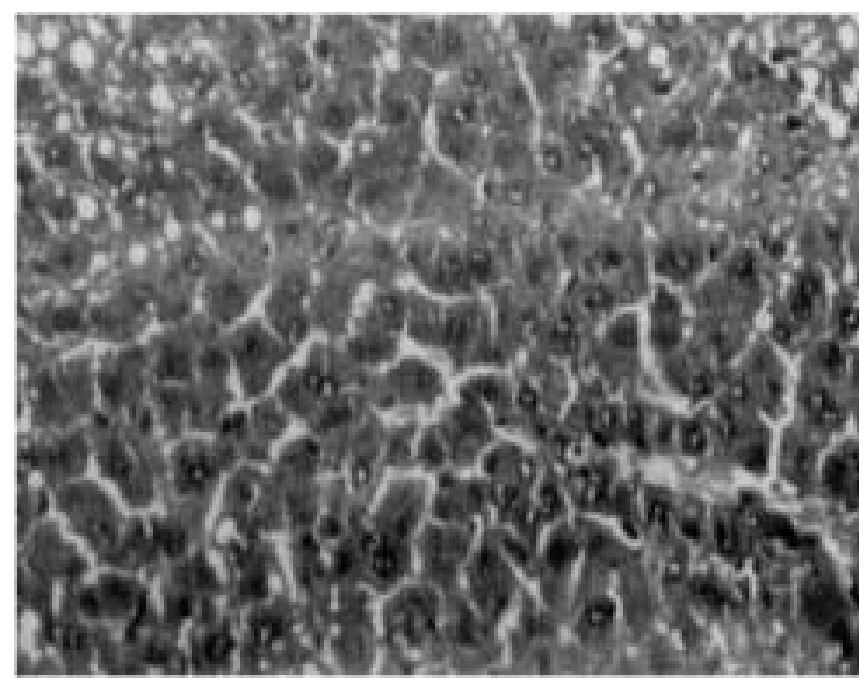

Liver tissue of rats treated with $\mathrm{LA}(200 \mathrm{mg} / \mathrm{kg})$ :

Signs of amelioration of $\mathrm{CCl}_{4}$-induced liver injury, ie., less degree of infiltration absence of necorsis, mild fatty change.

III and IV. Because hepatotoxic effect of $\mathrm{CCl}_{4}$ is due to oxidative damage by free radical generation, antioxidant property is claimed to be one of the mechanisms of hepatoprotective drugs. Further flavonoids have been suggested to act as antioxidants by free radical scavenging. Thus the hepatoprotective activity of LA may be attributed to the presence of flavonoids, though it is to be confirmed.

\section{K. Mangathayaru*, X. Fatima Grace, M. Bhavani, E. Meignanam, S.L. Rajasekhar Karna, D. Pradeep} Kumar

Sri Ramachandra College of Pharmacy, Sri Ramachandra Medical College and Research Institute (DU), Porur, Chennai-600 116. India E-mail: kvmanga@yahoo.com

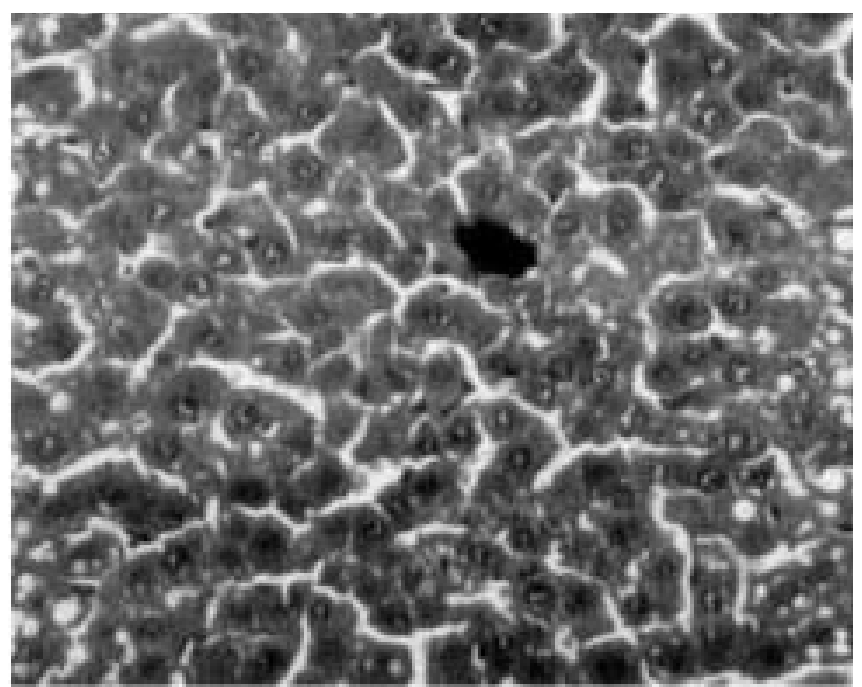

Liver tissue of rats treated with silymarin:

Practically complete recovery. Normal hepatocyte morphology.

\section{References}

1. Chopra RN, Nayar SL, Chopra IC. Glossary of Indian Medicinal Plants. New Delhi: NISCAIR, CSIR; 2002.

2. Misra TN, Singh RS, Pandey HS, Singh S. Long chain compounds from Leucas aspera. Phytochemistry 1992;31:1809-10.

3. Misra TN, Singh RS, Prasad C, Singh S. Two aliphatic ketols from Leucas aspera. Phytochemistry 1993;32:199-201.

4. Misra TN, Singh RS, Pandey HS, Singh S. A novel phenolic compound from Leucas aspera. Indian J Chem 1995;34:1108-10.

5. Pradan BP, Chakraborty DK, Subba GC. A Triterpenoid lactone from Leucas aspera. Phytochemistry 1990;29:1693-1965.

6. Jalalpure SS, Patil MB, Prakash NS, Hemalata K, Manvi FV. Hepatoprotective activity of fruits of Piper longum Linn. Indian J Pharm Sci 2003;65:363-6.

7. Reitmen S, Frankel AS. A colorimetric method for the determination of serum glutamic oxaloacetic and glutamic pyruvic transaminase. Am J Clin Pathol 1957;28;53-6.

8. Recknagel RO, Glende EA, Hruszkewyez AM. Free radicals in Biology. In: Proyer EA, editor. Vol.3. Academic Press; 1976. p. 97.

\section{Join "IndPharm" \\ IJP uses "IndPharm" to broadcast announcements. Want to join? Please E-mail: adithan@vsnl.com}

